\title{
Endoscopic Management of Mallory-Weiss Tearing
}

\author{
Hyun-Soo Kim \\ Department of Internal Medicine, Chonnam National University Medical School, Gwangju, Korea
}

\begin{abstract}
Mallory-Weiss tearing (MWT) is a common cause of non-variceal upper gastrointestinal bleeding. Although the majority of patients with bleeding MWT require no intervention other than hemodynamic supports, spectrum of MWT is wide, and the condition sometimes results in a fatal outcome. Endoscopic management to stop the bleeding may be required during the index endoscopy, especially in those with active bleeding or stigmata of recurrent bleeding. Most commonly used endoscopic treatment for actively bleeding MWT is injection therapy, argon plasma coagulation, hemoclip placement, and band ligation. Selection of the optimal endoscopic hemostasis depends on the physician's ability and patient's clinical status.
\end{abstract}

Key Words: Mallory-Weiss; Endoscopy; Therapeutics

\section{INTRODUCTION}

Mallory-Weiss tearing (MWT) is characterized by linear, non-perforating mucosal laceration at the lower part of the esophagus and/or upper part of the stomach. Mallory and Weiss first described MWT in 15 alcoholic patients with retching and vomiting in 1929. ${ }^{1}$ MWT rarely occurs after retching during endoscopic examination. It is a common cause of nonvariceal upper gastrointestinal (UGI) bleeding, with an incidence of $5 \%$ to $15 \% .^{2}$ Although most patients with bleeding MWT require no intervention other than hemodynamic support, the spectrum of MWT is wide, and the condition sometimes results in a fatal outcome. Endoscopic management to stop the bleeding may be required during the index endoscopy, especially in those with active bleeding or stigmata of recurrent bleeding.

\section{ENDOSCOPIC MANAGEMENT}

\section{Indication}

MWT is a common cause of non-variceal UGI bleeding.

Received: February 17, 2015 Accepted: February 25, 2015

Correspondence: Hyun-Soo Kim

Department of Internal Medicine, Chonnam National University Medical School, 42 Jebong-ro, Dong-gu, Gwangju 501-757, Korea

Tel: +82-62-220-6215, Fax: +82-62-228-1330, E-mail: dshskim@jnu.ac.kr

(c) This is an Open Access article distributed under the terms of the Creative Commons Attribution Non-Commercial License (http://creativecommons.org/ licenses/by-nc/3.0) which permits unrestricted non-commercial use, distribution, and reproduction in any medium, provided the original work is properly cited.
Although most bleeding stops spontaneously andmost patients can be managed with observation or conservative medical treatment, some patients require endoscopic or surgical treatment. The need for intensive care, including endoscopic hemostasis, has been proposed for patients with risk factors such as portal hypertension or coagulopathy. Endoscopic examination for diagnosis and treatment is required in patients with active bleeding MWT (e.g., arterial spurting and diffuse oozing). Stigmata (e.g., non-bleeding visible vessel and adherent clots) on index endoscopy do not necessarily require endoscopic treatment unless a rebleeding episode has occurred or they are associated with coagulopathy. Endoscopic hemostasis is the treatment of choice in such cases. The most commonly used endoscopic treatments for actively bleeding MWT are injection therapy, contact thermal treatment, argon plasma coagulation (APC), hemoclip placement, and band ligation (Fig. 1).

\section{Endoscopic injection therapy}

Various agents are used in endoscopic injection therapy but epinephrine is used most frequently. Injection therapy is a simple, easily applicable and relatively inexpensive first-line therapy. Epinephrine injection therapy improves outcomes in terms of rate of recurrent bleeding, hospital stay, and transfusion requirement compared with supportive measures alone. ${ }^{3}$ However, use of epinephrine for injection therapy can result in ventricular tachycardia because it is absorbed into the systemic circulation. Injection therapy should be avoided in patients with a history of coronary artery disease. Furthermore, con- 
troversy still exists regarding the volume of epinephrine needed for hemostasis. The hemostatic mechanisms of locally injected epinephrine are vascular contraction, mechanical compression against vessels, and platelet aggregation. Among these, mechanical compression is the most essential factor in the treatment of bleeding. Therefore, large-volume injection of epinephrine may be superior for preventing recurrent bleeding because of prolongation of mechanical vascular compression and vasoconstriction. However, it should be carefully administered because of the risk of systemic toxicity. A prospective, randomized study showed no observed rebleeding with largevolume epinephrine injection therapy. ${ }^{4}$

The hemostatic effect of epinephrine injection therapy alone in bleeding MWT is controversial. In one study, primary hemostasis of injection therapy was $100 \%$, but the rebleeding rate was $5.8 \%$ to $44 \% .{ }^{5}$ Several studies have reported that epineph-

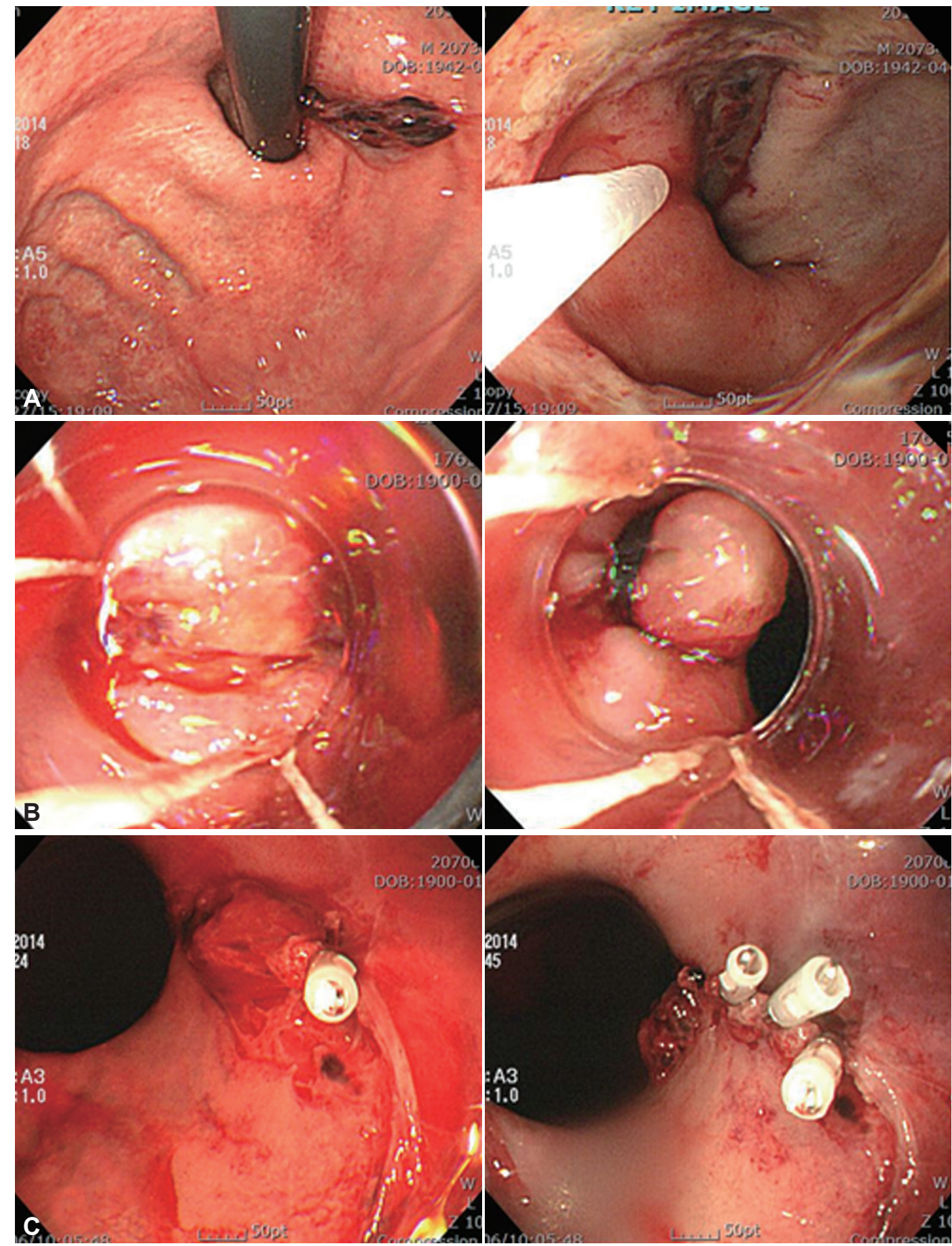

Fig. 1. Endoscopic treatment of Mallory-Weiss tearing. (A) Injection therapy. (B) Band ligation. (C) Hemoclipping. 
rine injection therapy alone in actively bleeding MWT could lead to an increase in recurrent bleeding compared with mechanical hemostasis or combination therapy. Epinephrine injection therapy in MWT may be insufficient for patients with a large and/or long plexus of vessels. ${ }^{6}$ For these reasons, epinephrine injection should be performed as combined therapy in MWT.

\section{Endoscopic electrocoagulation}

Simultaneous heat and pressure application to the bleeding lesion is possible by electrocoagulation. The effectiveness of coagulation in a wet field, such as a bleeding site, is decreased because the liquid dissipates the heat quickly. Proper positioning of the device has been quite demanding for lesions located on the lesser curvature of the cardia. Multipolar electrocoagulation has improved hemostasis significantly, reduced surgery in patients with actively bleeding MWT, and caused few complications. ${ }^{7}$ However, repetitive coagulation bears the risk of transmural injury and perforation because of the relatively thin esophageal wall and lack of serosa at the tear site.

APC is also used to treat bleeding MWT. The probe is placed at some distance from the site, and high-frequency electrical current results in coagulation of the bleeding lesion. The lack of contact between the catheter and the tissue results in a superficial burn, reducing unwanted tissue damage and perforation.

\section{Endoscopic hemoclip placement}

Endoscopic hemoclip placement is an easy-to-use procedure for treating bleeding lesions in nonfibrotic tissue such as MWT or Dieulafoy ulcer. However, because of the MWT bleeding location at the gastroesophageal (GE) junction, hemoclip placement is challenging and is probably more technically difficult. A recently developed rotational mechanism on the delivery catheter allows controlled orientation of the hemoclip and easy access to the GE junction. However, hemoclip detachment in the GE junction is frequently seen because of high amplitude contractions at this anatomic site. In the case of a deeper tear extension such as with Boerhaave syndrome, endoclip placement can fix both tearing edgesto close the perforated lesion. Application of clips and endoloops in large-diameter and long esophageal tears to bring together the edges of the tears has also been reported. ${ }^{8}$

In a Japanese study of endoscopic hemostasis with metallic hemoclips for iatrogenic and other causes of MWT, initial hemostasis was $100 \%$ in both groups; rebleeding was $0 \%$ in the former group and 5\% in the latter group. ${ }^{9}$ Another study, comparing the efficacy of band ligation and hemoclip placement in patients with bleeding MWT, found that the two procedures were equivalent for primary hemostasis (100\%) and rebleeding rate (6\% vs. $10 \%$, respectively). ${ }^{10}$ Thus, hemoclip place- ment and band ligation seem to provide safe and effective management of bleeding MWT. However, in combined therapy with epinephrine injection and hemoclipping, prior injection of epinephrine could lead to tissue edema at the bleeding site, which can interrupt clip placement or promote clip detachment. $^{11}$

\section{Endoscopic band ligation}

The main advantage of endoscopic band ligation (EBL) is its technical ease compared with other hemostatic procedures. In EBL, the lesion is well viewed tangentially under direct pressure from a transparent ligation cap. EBL is highly useful for bleeding lesions in nonfibrotic tissue, and esophageal perforation nearly occurs. The transparent cap facilitates the performance of EBL by immobilizing the bleeding site and eliminating movement from peristalsis and belching. The visible vessel is ligated in its deeper aspect, providing definitive hemostasis and firm placement of the ligated band. Moreover, large MWT can be treated with one single band ligation.

In a French study, EBL was safe and efficient for primary hemostasis of bleeding MWT. Furthermore, significantly less recurrent bleeding occurred in patients treated with EBL compared with hemoclips combined with epinephrine. ${ }^{11}$

\section{OUTCOMES}

Initial hemostatic ratios for MWT are given as $94 \%$ to $100 \%$ for endoscopic hemoclipping, 100\% for EBL, 93\% to 100\% for endoscopic injection therapy, and 77\% for endoscopic electrocoagulation. Several complications have been reported in endoscopic treatment of MWT, such as ventricular tachycardia after epinephrine injection ${ }^{12}$ and esophageal perforation after injection or coagulation therapy. ${ }^{13}$ A study of predictive factors for recurrent bleeding in MWT was performed in Korea. ${ }^{14} \mathrm{Re}-$ current bleeding was seen in $17(10.7 \%)$ of 159 patients with MWT and was associated with shock at initial manifestation and evidence of active bleeding on endoscopic examination. Other known risk factors of rebleeding of MWT are coagulopathy and low hemoglobin levels. ${ }^{15}$

\section{CONCLUSIONS}

MWT is an important common cause of UGI bleeding, and most MWT bleeding stops spontaneously. For actively bleeding MWT, the most frequently used endoscopic treatments are injection therapy, APC, hemoclip placement, and band ligation. Selection of the optimal approach to endoscopic hemostasis depends on the physician's ability and the patient's clinical status. 


\section{Conflicts of Interest}

The author has no financial conflicts of interest.

\section{REFERENCES}

1. Mallory GK, Weiss S. Hemorrhagic from laceration of the cardiac orifice of the sotmach due to vomiting. Am J Med Sci 1929;178:506-514.

2. Katz PO, Salas L. Less frequent causes of upper gastrointestinal bleeding. Gastroenterol Clin North Am 1993;22:875-889.

3. Llach J, Elizalde JI, Guevara MC, et al. Endoscopic injection therapy in bleeding Mallory-Weiss syndrome: a randomized controlled trial. Gastrointest Endosc 2001;54:679-681.

4. Park CH, Min SW, Sohn YH, et al. A prospective, randomized trial of endoscopic band ligation vs. epinephrine injection for actively bleeding Mallory-Weiss syndrome. Gastrointest Endosc 2004;60:22-27.

5. Peng YC, Tung CF, Chow WK, et al. Efficacy of endoscopic isotonic saline-epinephrine injection for the management of active MalloryWeiss tears. J Clin Gastroenterol 2001;32:119-122.

6. Terada R, Ito S, Akama F, et al. Mallory-Weiss syndrome with severe bleeding: treatment by endoscopic ligation. Am J Emerg Med 2000;18: 812-815.

7. Laine L. Multipolar electrocoagulation in the treatment of active upper gastrointestinal tract hemorrhage. A prospective controlled trial. N Engl J Med 1987;316:1613-1617.
8. Ivekovic H, Rustemovic N, Brkic T, et al. The esophagus as a working channel: successful closure of a large Mallory-Weiss tear with clips and an endoloop. Endoscopy 2011;43(Suppl 2 UCTN):E170.

9. Shimoda R, Iwakiri R, Sakata H, et al. Endoscopic hemostasis with metallic hemoclips for iatrogenic Mallory-Weiss tear caused by endoscopic examination. Dig Endosc 2009;21:20-23.

10. Cho YS, Chae HS, Kim HK, et al. Endoscopic band ligation and endoscopic hemoclip placement for patients with Mallory-Weiss syndrome and active bleeding. World J Gastroenterol 2008;14:2080-2084.

11. Lecleire S, Antonietti M, Iwanicki-Caron I, et al. Endoscopic band ligation could decrease recurrent bleeding in Mallory-Weiss syndrome as compared to haemostasis by hemoclips plus epinephrine. Aliment Pharmacol Ther 2009;30:399-405.

12. Stevens PD, Lebwohl O. Hypertensive emergency and ventricular tachycardia after endoscopic epinephrine injection of a Mallory-Weiss tear. Gastrointest Endosc 1994;40:77-78.

13. Bataller R, Llach J, Salmerón JM, et al. Endoscopic sclerotherapy in upper gastrointestinal bleeding due to the Mallory-Weiss syndrome. Am J Gastroenterol 1994;89:2147-2150.

14. Kim JW, Kim HS, Byun JW, et al. Predictive factors of recurrent bleeding in Mallory-Weiss syndrome. Korean J Gastroenterol 2005;46:447-454.

15. Kortas DY, Haas LS, Simpson WG, Nickl NJ 3rd, Gates LK Jr. MalloryWeiss tear: predisposing factors and predictors of a complicated course. Am J Gastroenterol 2001;96:2863-2865. 